\title{
Relationship between Perceived Organizational Support and Quality of Nurses' Work Life at King Fahad Hospital-Saudi Arabia
}

\author{
Salha Malki ${ }^{\star 1}$, Ghada Hamouda ${ }^{2}$, Ohood Felemban ${ }^{3}$ \\ ${ }^{1}$ Faculty of Nursing, King Abdulaziz University, Saudi Arabia \\ ${ }^{2}$ Assistant Professor of Nursing Administration, Faculty of Nursing, Alexandria University, Alexandria, Egypt- Associate Prof. of \\ Nursing Administration, King Abdul-Aziz University, Jeddah, KSA \\ ${ }^{3}$ Public Health Department, Faculty of Nursing, King Abdulaziz University, Saudi Arabia
}

https://doi.org/10.15520/ijmhs.v10i10.3136

Accepted 20/09/2020; Received 12/08/2020; Publish Online 31/10/2020

\begin{abstract}
Background: Improving the quality of nurses' working life is challenging for healthcare organizations because of its effect on the staff, organizations, and customers. The development of supportive environments will enhance the quality of nursing work life in organizations. However, the association between perceived organizational support and the quality of working life among nurses was limited information.

Aim: This study aims to assess the relationship between perceived organizational support and the quality of nurses' work life at a King Fahad Hospital Jeddah, Saudi Arabia.

Methodology: This current study was conducted at King Fahad Hospital, Jeddah, Saudi Arabia. A descriptive correlational design was used. A convenience sampling technique was implemented to gather the needed data using a self-report questionnaire. Data was collected using the Survey of Perceived Organizational Support and Brook' Quality of Nursing Work Life Survey. In addition, a demographic questionnaire was developed by the researcher.

Results: About $80.6 \%$ of staff nurses showed a moderate POS level, and $63.6 \%$ of staff nurses experienced an average level of QNWL. The Pearson correlation coefficients showed a statistically significant correlation between POS and overall QNWL (0.541). The correlations between POS and the sub-scales of QNWL came in the range $(0.367$ - 0.521). Also, it found that non-Saudi nurses exhibited higher POS and QNWL levels compared to Saudi nurses.

Conclusion and Recommendation: The study found that perceived organizational support is positively related to QNWL, which means that the higher nurses' perceived organizational support will improve the nurses' quality of working life. These findings should be used by nursing administrations and health policymakers to develop a series of organizational support that can improve the quality of working life among nurses. Future research, further comparative research is needed to examine POS and its relation to QNWL among different healthcare organizations.
\end{abstract}

Key words: Perceived Organizational Support-Quality of Nurses' Work Life-Quality of Nursing Work Life-Staff nurses

\footnotetext{
${ }^{\star}$ Corresponding author.

$\dagger$ Email: ms22.almalki@gmail.com.
}

Today's competitive, challenging, and changing the work environment, replete with job uncertainty, and contribute to the lack of trust and concern for the mutual welfare between employees and employers [1]. Many employers should understand the central importance 
of favorable relationships with staff in enhancing dedication to organizational goals and growing efficiency [1]. Organizational support is one of the main principles that retain and improve employee relationships in the organization [2].

According to the theory of organizational support, "employees develop an overall perception and belief to which their work organization values their contribution and cares about their well-being and interests (perceived organizational support, or POS)" $[3,4]$. Employees who feel supported experience their working lives in more favorable ways, feel a more positive mood at work, more satisfied with their jobs, believe they make meaningful contributions, experience less stress, and are less conflicted regarding family life and work [5]. Additionally, Jahani et al. suggested that with an increase in staff's perceived organizational support it could improve their working life quality [6].

Quality of nurses' work life defined by Brooks [7] as "the degree to which registered nurses are able to satisfy important personal needs through their experiences in their work organization while achieving the organization's goals". Two mains goals for QNWL, which improve the quality of employee working experience and at the same time improve the overall organization productivity [7, 8]. In order to attract new staff and retain employees, it is necessary to improve quality of working life. It would offer many benefits for employees, institutions, and clients, for example, increasing the commitment to work and enhancing service efficiency [8].

Review recent studies regarding the perceived organizational support level, and few studies reported perceived organizational support at a moderate level among nurses in different healthcare settings $[9,10]$. However, perceived organizational support was reported at a low level in recent studies conducted in different countries[11-13]. In addition, numerous reports have recognized the quality of working life among nurses globally. The quality of work life among nursing was found at moderate levels in various recent studies [14-20]. Other researchers have documented nurses were dissatisfied with the quality of their work life [21-24]. An examination of prior literature limited studies illustrated the correlation between perceived organizational support and quality of working life among nurses $[6,25]$.

Furthermore, several challenges are faced by the nursing profession as a shortage of nurses, a high turnover rate, work-family conflict, lack of training opportunities, increased workload, and insufficient support system [26]; this can effect working life quality of nurses. According to Objectives of KSA Vision 2030, "enhance government effectiveness," [27], the Ministry of Health in Saudi Arabia is seeking to improve organizational efficiency, nursing retention, work performance, productivity, nursing job satisfaction, and patient care, which can achieve through enhancing the quality of nursing work life.

However, upon the researcher knowledge, there was no studies were done in Saudi Arabia to investigate the relationship between perceived organizational support and the quality of working life among nurses in Saudi Arabia during an electronic database search.

This study is important to fill national and international research gaps by developing valuable evidence on the relationship between perceived organizational support and the 
quality of the working life among nurses. This study aimed to assess the relationship between perceived organizational support and quality of nurses' work life at King Fahad hospital-Saudi Arabia. Additionality, the main objectives of this study were as follows: (a) to identify the level of perceived organizational support among staff nurses; (b) to measure the level of QNWL; (c) to examine the correlation among perceived organizational support and the quality of nurses' work life at a King Fahad hospital.

\section{METHODS}

\section{Study Design}

This research used a descriptive correlation design.

\section{Study Setting}

This current study was at King Fahad hospital, Jeddah city, Saudi Arabia. It is considered one of the biggest hospitals in the western region in the Ministry of Health with 707 beds capacity. Additionally, this hospital provides a comprehensive range of tertiary care services, including diagnostic specialties and therapeutics services in internal medicine, ICU, emergency cardiology, other medical services, and functions as a referral center for other hospitals in Jeddah city. Data collected from the inpatient department serves different units; (general unit such as medical, surgical, orthopedic el, and specialized units such as; ICU, CCU).

\section{Subjects}

A convenience sample technique was applied to recruited staff nurses. Using the Online Epi Info calculating program with the margin of error 5\%, response distribution $50 \%$ at a confidence level of $95 \%$ to calculated sample size. Thus, according to the equation above, the sample consisted of 254 staff nurses. Also, the inclusion criteria in the study staff nurses working at KFHJ, giving direct and indirect patient care with at least one year of experience, Saudi \& non-Saudi staff, male \& females nurses. This study excluded nurse working in the administrative and educational position.

\section{Data collection tool}

In this study, a self-administered questionnaire was considered as the most appropriate data collection instrument. Hence, the questionnaire used in this study constitutes three sections as follow:

Part I: It includes the following information about sociodemographic characteristics: "age, gender, marital status, nationality, educational level, working unit, and years of experience."

\section{Part II: Survey of Perceived organizational support}

Perceived Organizational Support Survey was developed by Eisenberger et al. (1986) to assess the employees' perceptions of organizational support. It is comprised of 16 items. Every item in this survey scored according to a 7-point Likert scale ranging from "1= Strongly Disagree" to "7= Strongly Agree". The total score ranges from 16 to 112. The higher scores suggest higher organizational support perceptions. Additionally, interpreting scores for POS as follow:

- 1-38 indicate low POS.

- 38 - 75 indicate moderate POS.

- 75 - 112 indicate high POS.

\section{Part III: Quality of Nurses' Work Life} Survey

Quality of Nursing Work Life Survey was developed by Brooks (2001) to measure nurses' perception of their quality of working life. The scale consists of 42 items, which are 
classified into four main dimensions; "work life/home life," which consists of seven items. The "work design" dimension, it consists of ten items. The "work context" dimension, it consists of 20 items. Finally, the "work world" dimension, consisting of five items. Also, the tool measured participating nurses how often they agree or disagree on a 6-point Likert scale with each item range from 1 "strongly disagree" to 6 "strongly agree." The average minimum score is 42 , and 252 is the maximum score. The higher score reveals high levels of QNWL [7, 28]. Additionally, interpreting scores for QNWL as follow:

- 42-112 indicate low QNWL

- 113-182 indicate moderate QNWL

- 183-252 indicate high QNWL

\section{Validity and Reliability}

For the current study, the researcher examined the content validity to determine a questionnaire's accuracy. Questionnaires have been validated by five academic experts from faculty members after the original English format (questionnaires) translated to the Arabic language using a translating and backtranslated technique. In addition, no modifications were made. Additionally, both tools used for data collection tested for reliability by using Cronbach's Alpha coefficient and results as follows; POS; 0.762 and Overall QNWL; 0.928.

\section{Pilot Study}

In this study, to determine the overall clarity and estimate the time needed for data collection, a pilot study was carried out on ten percent (25 staff nurses) of the sample size, and no alteration was done in the questionnaires after the pilot study. So, the pilot sample was included in the study sample.

\section{Data collection}

The approval for the research was obtained from the IRB at Jeddah Health Affairs. By direct contact with the investigator at the hospital site. At each unit, the researcher met the departments' managers, then distributed questionnaires to staff nurses after explaining the study's purpose, and invited them to participate in the study. The response rate was 97 percent after the inappropriate questionnaires were excluded. Moreover, all data were collected over three weeks between 01-19 March 2020.

\section{Ethical Consideration}

Official approval from the Ethics committee of the Faculty of Nursing College at King Abdulaziz University was obtained to conduct the study, and approval was also obtained from the Institution Review Board at Directorate of the Health Affairs Jeddah. Finally, before data collection, the IRB's approval is submitted to the target hospital.

Furthermore, the ethical aspects of the study undertaken on the principles of research ethics. The researcher respected the participants' anonymity and confidentiality, and the right to withdraw from the study until the data collection stage was complete. The study has no potential or real harm to personal or professional associated participation in this study.

\section{Data analysis}

Data obtained from all the tools were coded and analyzed using the software version (24) of the Statistically Package for Social Sciences (SPSS) for statistically analysis purposes. The author used the statistical processes that included descriptive analysis, the Pearson Correlation Coefficient, samples t-test, and one-way analysis of variance (ANOVA). Also, to test the reliability of both tools, Cronbach's Alpha test was used. 


\section{RESULTS}

Table (1) showed that, the study participants consisted of 247 staff nurses; more than half of the nurses $(51.4 \%)$ were aged between groups (30-39 years). Most of the participants $(91.1 \%)$ were female, and two-thirds $(65.6 \%)$ of staff nurses were married. Regarding the nationality, $(42.5 \%)$ of the staff nurses were Saudis, while $(57.5 \%)$ are non-Saudis. The staff nurses' education level demonstrated that almost two-thirds $(71.3 \%)$ had a baccalaureate degree, whereas less than one third (28.7\%) had a diploma. In terms of working units, (86.6\%) of staff nurses who participated in this study were represented from general units, while $(13.4 \%)$ of nurses work in special units (ICU, CCU). In terms of years of experience, the data analysis showed that $(80.6 \%)$ of the staff nurses have less than ten years of experience, while $(19.5 \%)$ had more than ten years of working experience.

Table (1) Number and Percentage Distribution of Staff Nurses according to Sociodemographic characteristics $(n=247)$.

\begin{tabular}{|c|c|c|c|}
\hline \multirow[t]{2}{*}{ Sociodemographic characteristics } & \multirow[t]{2}{*}{ Categories } & \multicolumn{2}{|c|}{$\overline{n=247}$} \\
\hline & & $\overline{\mathbf{N} .}$ & $\%$ \\
\hline \multirow[t]{4}{*}{ Age } & $20-29$ years & 96 & $38.9 \%$ \\
\hline & $30-39$ years & 127 & $51.4 \%$ \\
\hline & $40-49$ years & 21 & $8.5 \%$ \\
\hline & $\geq 50$ years & 3 & $1.2 \%$ \\
\hline \multirow[t]{2}{*}{ Gender } & Male & 22 & $8.9 \%$ \\
\hline & Female & 225 & $91.1 \%$ \\
\hline \multirow[t]{3}{*}{ Marital Status } & Single & 77 & $31.2 \%$ \\
\hline & Married & 162 & $65.6 \%$ \\
\hline & Divorced/Widowed & 8 & $3.2 \%$ \\
\hline \multirow{2}{*}{ Nationality } & Saudi & 105 & $42.5 \%$ \\
\hline & Non-Saudi & 142 & $57.5 \%$ \\
\hline \multirow[t]{2}{*}{ Education Level } & Diploma & 71 & $28.7 \%$ \\
\hline & Bachelor & 176 & $71.3 \%$ \\
\hline \multirow[t]{6}{*}{ Working Unit } & Medical & 51 & $20.6 \%$ \\
\hline & Surgical & 49 & $19.8 \%$ \\
\hline & Orthro & 56 & $22.7 \%$ \\
\hline & Intensive Care Unit (ICU) & 16 & $6.5 \%$ \\
\hline & Cardiac Care Unit (CCU) & 17 & $6.9 \%$ \\
\hline & Other & 58 & $23.5 \%$ \\
\hline \multirow[t]{4}{*}{ Years of Experience } & $1-5$ years & 102 & $41.3 \%$ \\
\hline & $6-10$ years & 97 & $39.3 \%$ \\
\hline & $11-15$ years & 34 & $13.8 \%$ \\
\hline & $>15$ years & 14 & $5.7 \%$ \\
\hline Total & & 247 & $100.0 \%$ \\
\hline
\end{tabular}


As shown in table 2, the mean perceived organizational support was moderate (66.12), and the mean score of QNWL was moderate (168.85). Regarding the sub-scales of QNWL, it was found that work design, work life / home life, and work world had a moderate level $(40.9,24.05,19.00)$, respectively, while work context had a high level (84.88).

Table (2) Mean and standard deviation of nurses' perceived organizational support and the quality of nurses' work life ( $\mathrm{n}=247)$.

\begin{tabular}{ccccc}
\hline \hline Variable & Range & Mean & SD & Level \\
\hline \hline POS & $24-106$ & 66.12 & 12.32 & Moderate \\
\hline Overall QNWL & $64-241$ & 168.85 & 27.33 & Moderate \\
Work life /Home life & $7-37$ & 24.05 & 6.46 & Moderate \\
Work Design & $12-58$ & 40.91 & 6.88 & Moderate \\
Work Context & $31-120$ & 84.88 & 14.46 & High \\
Work World & $6-30$ & 19.00 & 4.23 & Moderate
\end{tabular}

Table (3) showed Pearson correlation coefficients' results for the relationship between POS and QNWL and its sub-scales. It was found that there is a statistically positive significant correlation between POS and overall QNWL (0.541). The correlations between POS and the sub-scales of QNWL came in the range $(0.367-0.521)$, which are positive and statistically significant at level (0.01). The highest relationship reported between POS and work context, which is (0.521), then the relationship with work life / home life which is (0.489), then work design which is (0.369), and the lowest relationship was reported between POS and work world which is $(0.367)$. These results mean that the increase in nurses' perception of organizational was subsequently increase in the level of QNWL and its sub-scales.

Table (3) Correlation between nurses' perceived organizational support and quality of nurses' work life $(n=247)$.

\begin{tabular}{ccc}
\hline \hline \multirow{2}{*}{ QNWL } & \multicolumn{2}{c}{ Perceived Organizational Support (POS) } \\
\cline { 2 - 3 } & Pearson Correlation & p-value \\
\hline Work life/ Home life & $0.489^{* *}$ & 0.000 \\
\hline Work Design & $0.369^{* *}$ & 0.000 \\
\hline Work Context & $0.521^{* *}$ & 0.000 \\
\hline Work World & $0.367^{* *}$ & 0.000 \\
\hline Overall QNWL & $0.541^{* *}$ & 0.000 \\
\hline
\end{tabular}

** Correlation is significant at the level $(<0.01)$. 
Table (4) illustrated that the mean score for

QNWL levels than Saudi nurses. non-Saudi nurses exhibited higher POS and

Table (4) Correlation between nurses' perceived organizational support and quality of nurses' work life according to sociodemographic characteristics $(n=247)$.

\begin{tabular}{|c|c|c|c|c|c|c|c|c|c|}
\hline \multirow[b]{2}{*}{ Variables } & \multirow[b]{2}{*}{ Categories } & \multicolumn{4}{|c|}{$\overline{P O S}$} & \multicolumn{4}{|c|}{ 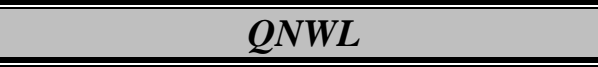 } \\
\hline & & 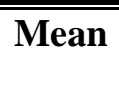 & $\overline{\overline{\text { SD }}}$ & $\begin{array}{c}\mathbf{t} / \mathbf{F} \\
\text { value }\end{array}$ & $\overline{p \text { p-value }}$ & $\overline{\text { Mean }}$ & $\overline{\overline{\text { SD }}}$ & $\begin{array}{c}\mathbf{t} / \mathbf{F} \\
\text { value }\end{array}$ & $\overline{p \text { p-value }}$ \\
\hline$\overline{\overline{\text { Age }}}$ & 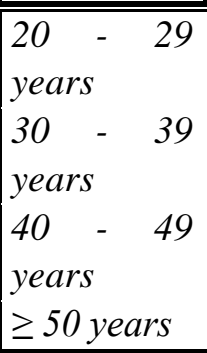 & $\begin{array}{l}66.64 \\
65.40 \\
68.00 \\
66.67 \\
\end{array}$ & $\begin{array}{l}12.44 \\
12.55 \\
11.38 \\
1.15 \\
\end{array}$ & 0362 & $\overline{0.780}$ & $\begin{array}{r}170.22 \\
166.47 \\
172.33 \\
201.00 \\
\end{array}$ & $\begin{array}{l}27.17 \\
26.46 \\
32.42 \\
8.19 \\
\end{array}$ & 101.919 & $\overline{0.127}$ \\
\hline$\overline{\text { Gender }}$ & $\begin{array}{l}\text { Male } \\
\text { Female }\end{array}$ & $\begin{array}{l}61.91 \\
66.53 \\
\end{array}$ & $\begin{array}{l}11.15 \\
12.37 \\
\end{array}$ & $\begin{array}{c}- \\
1.685\end{array}$ & 0.093 & $\begin{array}{l}159.41 \\
169.77 \\
\end{array}$ & $\begin{array}{l}31.08 \\
26.84 \\
\end{array}$ & $\begin{array}{c}- \\
1.703\end{array}$ & 0.090 \\
\hline $\begin{array}{c}\text { Marital } \\
\text { Status }\end{array}$ & $\begin{array}{l}\text { Single } \\
\text { Married } \\
\text { Divorced } \\
\end{array}$ & $\begin{array}{l}64.99 \\
66.90 \\
61.13 \\
\end{array}$ & $\begin{array}{l}13.18 \\
11.74 \\
14.84 \\
\end{array}$ & 1.313 & $\overline{0.271}$ & $\begin{array}{l}167.45 \\
170.02 \\
158.38 \\
\end{array}$ & $\begin{array}{l}28.99 \\
26.68 \\
24.15 \\
\end{array}$ & 0.836 & $\overline{0.435}$ \\
\hline "Nationality & $\begin{array}{l}\text { Saudi } \\
\text { Non-Saudi }\end{array}$ & $\begin{array}{l}63.10 \\
68.35 \\
\end{array}$ & $\begin{array}{l}12.92 \\
11.39 \\
\end{array}$ & $\begin{array}{c}- \\
3.386\end{array}$ & $\overline{0.001 * *}$ & $\begin{array}{l}162.20 \\
173.76 \\
\end{array}$ & $\begin{array}{l}28.83 \\
25.16 \\
\end{array}$ & $\begin{array}{c}- \\
3.354\end{array}$ & $\overline{0.001 * *}$ \\
\hline $\begin{array}{c}\text { Education } \\
\text { Level }\end{array}$ & $\begin{array}{l}\text { Diploma } \\
\text { Bachelor } \\
\end{array}$ & $\begin{array}{l}64.76 \\
66.66 \\
\end{array}$ & $\begin{array}{l}12.64 \\
12.18 \\
\end{array}$ & $\begin{array}{c}- \\
1.100\end{array}$ & $\overline{0.272}$ & $\begin{array}{l}165.96 \\
170.01 \\
\end{array}$ & $\begin{array}{l}28.70 \\
26.76 \\
\end{array}$ & $\begin{array}{c}- \\
1.055\end{array}$ & $\overline{0.292}$ \\
\hline $\begin{array}{c}\text { Working } \\
\text { Unit }\end{array}$ & \begin{tabular}{|l} 
Medical \\
Surgical \\
Ortho \\
ICU \\
CCU \\
Other \\
\end{tabular} & $\begin{array}{l}65.55 \\
68.20 \\
63.45 \\
66.38 \\
67.41 \\
66.98 \\
\end{array}$ & $\begin{array}{c}11.88 \\
12.83 \\
13.05 \\
9.68 \\
11.76 \\
12.34 \\
\end{array}$ & 0.924 & $\overline{0.466}$ & $\begin{array}{l}168.24 \\
171.90 \\
167.43 \\
177.13 \\
174.47 \\
164.24 \\
\end{array}$ & $\begin{array}{l}33.63 \\
26.48 \\
24.58 \\
23.11 \\
23.22 \\
26.57 \\
\end{array}$ & 0.923 & $\overline{0.467}$ \\
\hline $\begin{array}{c}\text { Years of } \\
\text { Experience }\end{array}$ & $\begin{array}{lrr}1 & -5 & \text { years } \\
6 & - & 10 \\
\text { years } & \\
11 & - & 15 \\
\text { years } & \\
> & 15 & \text { years }\end{array}$ & $\begin{array}{l}67.55 \\
63.79 \\
66.82 \\
70.07 \\
\end{array}$ & $\begin{array}{l}12.79 \\
11.18 \\
13.72 \\
11.15\end{array}$ & 2.158 & $\overline{0.094}$ & $\begin{array}{r}168.36 \\
166.72 \\
172.65 \\
177.86\end{array}$ & $\begin{array}{l}28.81 \\
25.96 \\
27.97 \\
23.77\end{array}$ & 0.932 & $\overline{0.426}$ \\
\hline
\end{tabular}

\section{DISCUSSION}

This research has been carried out to assess the level of perceived organizational support and the quality of working life among staff nurses and to examine the relationship between these two variables.

\section{Level of POS and QNWL}

The results revealed moderate nurses' perception of organizational support, and this 
may be explained by the current study sample recruited from high bed capacities hospital. According to Labrague et al., bed capacity predicted the nurses' perception of organizational support and indicated a higher perception of organizational support among nurses working in the hospital's high bed capacity [12]. Additionally, Eisenberger et al. reported that POS had been influenced by significant antecedents, including fairness, human resource practices, work conditions, and leaders' support [4]. These antecedents may explain the level of nurses' perception of organizational support in this study's sample.

These results supported the finding of previous research in several countries. A study reported by Cheng et al. found that perceived organizational support was moderate among 300 nurses working in Chinese public hospitals [9]. Another study carried out among 500 nurses in Egypt reported moderate nurses' perceptions of organizational support [10]. Moreover, Gorji, Etemadi [29], carried out a study to evaluate the POS level and reported that nurses working in an emergency were at a moderate level of POS. However, this result inconsistent with other research that reported perceived organizational support at a low level among nurses [11-13, 30].

One interesting finding of the current study found QNWL at a moderate level and noted the highest level of QNWL regarding the dimension of "work context," while the "work life/home life," "work design," and "work world" presented average scores. This finding is consistent with a recent study in Saudi Arabia by Alharbi et al. among 400 nurses at Madinah region hospitals, aimed to identify levels of QNWL, reported that nurses had a moderate level of nursing working life quality [18]. Also, this finding supports the recent result of a study conducted in Bangladesh by
Akter, Akkadechanunt [15], aimed to evaluate the quality of working life of 288 nurses employed in six tertiary hospitals. The result showed the quality of nurses' work life was moderate.

However, QNWL has reported at a low level in some studies, which is opposite to our findings. These differences may be attributable to variations in institutional and individual. The survey among 2391 nurses from different Iranian public hospitals showed the quality of working life among nurses' was at a low level [24]. Additionally, in the study conducted by [23] in Saudi Arabia, nurses were dissatisfied with their quality of work life. Likewise, the study carried out in South Ethiopia reported that nurses were dissatisfied with the quality of their working life [22]. Another study undertaken in Iran aimed to assess nursing quality of work life revealed that quality of the nurses' work life, less than moderate [21].

\section{The Relationship of POS and QNWL}

The current study reported a positive, statistically significant correlation between perceived organizational support and QNWL and its dimensions. Moreover, the highest relationship reported between perceived organizational support and "work context," then the relationship with "work life/ home life," then "work design," and the lowest relationship reported between POS and "work world." Therefore, likely that such connections exist between nurses' perception of organizational support and quality of nurses' work life cannot be ignored. If nursing gets such support from their managers, they feel their contribution and extra effort to the hospitals are valued and appreciated. Consequently, this may raise their general satisfaction and lead to a higher working life quality. 
The similarity to this finding, a study carry out by Brunault, Fouquereau [25] reported a statistical relationship between perceived organizational support and quality of work life among 84 psychiatric nurses in French. Likewise, a study conducted in a healthcare setting in Iran by Jahani, Mahmoudi [6], aimed to assess a structural design of the relation between perceived organizational support and quality of working life among 350 medical personnel including physicians, nurses, administrative- financial, staff and other relevant workers were working at hospitals, the result showed that perceived organizational support associated with the quality of working life.

\section{Demographic characteristic and POS and QNWL}

In the current study, the perception of organizational support among staff nurses was substantially associated with nationality only; observed the non-Saudi nurses had slightly higher average perceived organizational support scores than Saudi nurses. However, why Saudi nurses have obtained less perceived organizational support than their peers, are not clear because there is a lack of evidence regarding perceived organizational support among nurses in the Saudi context. However, this may be related to their overall perception of organizational support regarding their opinions, well-being, performance, appreciation of extra effort, responses to their complaints, and satisfaction.

Furthermore, other demographic features, including "age, gender, marital status, education level, working unit, years of experience", was no significant association with nurses' perception of organizational support. The results are compatible with other studies conducted in Iran that found that there was no relationship between perceived organizational support and demographic characteristics as age, gender, marital status, level of education, and work experience [13]. In contrast, the current study results were inconsistent with the result reported by Abou Hashish [10], revealed that nurses' age and years of experience association with perception of organizational support. Moreover, another study conducted in Iran [29] reported that age had a positive, meaningful relationship with perceived organizational support and found that nurses with diploma licenses had higher perceived organizational support.

This study a shows significant differences in the QNWL and the nationality of staff nurses only. Non-Saudi nurses found that QNWL was substantially higher than Saudi nurses. Likewise, other studies found significant relations between nationality and quality of nurses' work life [8, 18]. In addition, this may be attributed to their general view of their working lives, including family requirements, career advancement, working conditions, financial advantages and the public image of nursing [8]. However, the other demographic variables, such as "age, gender, marital status, education level, working unit, years of experience," were not significant association with QNWL.

The results of this study showed age, not a significant relation with QNWL, it could explain that $90.3 \%$ of the participants in this study have age less than 40 years. This finding is in line with studies conducted in Jorden, South Ethiopia, and Turkey [16, 20, 22]. However, in other studies, older nurses have a substantially higher average quality of work life ratings than younger nurses [24]. Regarding gender, [8, 24] reported male nurses had a lower average of QNWL levels than female participants, which was 
inconsistent with our result of no difference between mean scores of males and females with their QNWL. It is in line with other study findings $[16,22]$

Concerning marital status, there was no correlation between QNWL and marital status in the current study result, and this similarity to the study conducted by $[16,22,23]$. This result was inconsistent with the research reported that single nurses had significantly lower average scores of QNWL [8, 24]. Moreover, recent study have shown that highly qualified nurses are more satisfied with their quality of work life [24]. In contrast, this study did not show any significant variations in the QNWL scores of nurses linked to the educational level. This finding corresponds to the studies that reported educational levels no significant to QNWL $[8,15,16]$.

An examination into the work unit as a demographic characteristic, this study found no meaningful difference in QNWL scores among nurses working in the various unit and that incongruent with findings of a previous nursing study [22, 31]. However, many previous studies in Saudi Arabia reported nurses with more experience years, they are more satisfied with their work life [8, 18, 23]. While this study's finding did not demonstrate any significant variations in the QNWL scores of nurses' staff connected to the length of experience, it could explain that $80.6 \%$ of the participants in this study have less than ten years of experience. It is in line with research results elsewhere $[15,22]$.

\section{CONCLUSIONS}

This study's finding revealed that perceived organizational support is positively related to the quality of nurses' work life, which means that a higher level of perceived organizational support will lead to a higher level of QNWL. It appeared that staff nurses in the current study have a moderate level of both perceptions of organizational support and the quality of nurses' work life. Additionally, it found that non-Saudi nurses exhibited higher POS and QNWL levels compared to Saudi nurses.

\section{Recommendations}

Based on the study findings, hospitals and nursing managers can provide a series of organizational support that optimizing nurses' perception of organizational support and contribute to enhancing nurses' quality of work life as the following recommendations: (a) Treat all staff nurses by the fair in evaluation, compensation, and promotion. (b) Provide practical training and educational opportunities to encourage professional development, (c) Hospital and nurse managers should improve the nursing work environment by providing staff nurses with the required equipment to perform their work effectively.

Further comparative research is needed to examine POS and QNWL levels and investigate relationships among these variables across different healthcare organizations such as government hospitals and other private hospitals. Moreover, qualitative research is required to explore the factors affecting organizational support and quality of nurses' work life among staff nurses.

\section{REFERENCES}

1. Eisenberger, R., G.P. Malone, and W.D. Presson, Optimizing perceived organizational support to enhance employee engagement. Society for Human Resource Management and Society for Industrial and Organizational Psychology, 2016. 2: p. 22. 
2. Colakoglu, U., O. Culha, and H. Atay, The effects of perceived organisational support on employees' affective outcomes: Evidence from the hotel industry. Tourism and hospitality management, 2010. 16(2): p. 125-150.

3. Eisenberger, R., et al., Perceived organizational support. Journal of Applied psychology, 1986. 71(3): p. 500 .

4. Eisenberger, R., L. Rhoades Shanock, and X. Wen, Perceived Organizational Support: Why Caring About Employees Counts. Annual Review of Organizational Psychology and Organizational Behavior, 2020. 7: p. 101-124.

5. Eisenberger, R. and F. Stinglhamber, Perceived organizational support: Fostering enthusiastic and productive employees. 2011: American Psychological Association.

6. Jahani, M.A., et al., Structural model of the relationship between perceived organizational support and quality of working life of employees of the selected hospital of north of Iran. Ambient Science, 2017. 4(1): p. 2327.

7. Brooks, B.A., Development of an instrument to measure quality of nurses' worklife. 2001.

8. Almalki, M.J., G. FitzGerald, and M. Clark, Quality of work life among primary health care nurses in the Jazan region, Saudi Arabia: a crosssectional study. Human resources for health, 2012. 10(1): p. 30.

9. Cheng, L., et al., Paediatric nurses' general self-efficacy, perceived organizational support and perceived professional benefits from Class A tertiary hospitals in Jilin province of China: the mediating effect of nursing practice environment. BMC Health Services Research, 2020. 20(1): p. 12.

10. Abou Hashish, E.A., Relationship between ethical work climate and nurses' perception of organizational support, commitment, job satisfaction and turnover intent. Nursing ethics, 2017. 24(2): p. 151-166.

11. Aly, N.A.E.-F.M., M. Ghanem, and S. El-Shanawany, Organizational Cynicism and Its Consequences on Nurses and Quality of Care in Critical Care and Toxicology Units. Journal of Education and Practice, 2016. 7(8): p. 85-96.

12. Labrague, L.J., et al. Perceptions of organizational support and its impact on nurses' job outcomes. in Nursing forum. 2018. Wiley Online Library.

13. Robaee, N., et al., Perceived organizational support and moral distress among nurses. BMC nursing, 2018. 17(1): p. 1-7.

14. Hemanathan, R., P.P. Sreelekha, and M. Golda, Quality of work life among nurses in a Tertiary Care Hospital. Health Care, 2017. 5(4): p. 555667.

15. Akter, N., et al., Factors predicting quality of work life among nurses in tertiary-level hospitals, Bangladesh. International nursing review, 2018. 65(2): p. 182-189.

16. Suleiman, K., et al., Quality of nursing work life and related factors among emergency nurses in Jordan. Journal of Occupational Health, 2019. 61(5): p. 398-406. 
17. Wang, Q.Q., et al., Job burnout and quality of working life among Chinese nurses: A cross-sectional study. Journal of Nursing Management, 2019. 27(8): p. 1835-1844.

18. Alharbi, M.F., et al., Quality of nursing work life among hospital nurses in Saudi Arabia: A crosssectional study. Journal of Nursing Management, 2019. 27(8): p. 17221730.

19. Wang, L., et al., Analysis and strategy research on quality of nursing work life. Medicine, 2020. 99(6).

20. Yildiz, M., Nursing's Job Life Quality's Effect on Job Satisfaction. International Journal of Caring Sciences, 2019. 12(2): p. 1-8.

21. Eslamian, J., A.A. Akbarpoor, and S.A. Hoseini, Quality of work life and its association with workplace violence of the nurses in emergency departments. Iranian journal of nursing and midwifery research, 2015. 20(1): p. 56.

22. Kelbiso, L., A. Belay, and M. Woldie, Determinants of quality of work life among nurses working in Hawassa town public health facilities, South Ethiopia: A cross-sectional study. Nursing Research and Practice, 2017. 2017.

23. Kaddourah, B., A.K. Abu-Shaheen, and M. Al-Tannir, Quality of nursing work life and turnover intention among nurses of tertiary care hospitals in Riyadh: a cross-sectional survey. BMC nursing, 2018. 17(1): $\mathrm{p}$. 43.

24. Raeissi, P., et al., Quality of work life and factors associated with it among nurses in public hospitals, Iran. Journal of the Egyptian Public Health Association, 2019. 94(1): p. 25.

25. Brunault, P., et al., Do transactive memory and participative teamwork improve nurses' quality of work life? Western Journal of Nursing Research, 2014. 36(3): p. 329-345.

26. Lamadah, S.M. and H.Y. Sayed, Challenges facing nursing profession in Saudi Arabia. Journal of Biology, Agriculture and Healthcare, 2014. 4(7): p. 20-25.

27. Bassi, J., Vision 2030 and the opportunities it represents in healthcare in Saudi Arabia. Retrieved February, 2016. 25: p. 2019.

28. Brooks, B.A., et al., Assessing the quality of nursing work life. Nursing Administration Quarterly, 2007. 31(2): p. 152-157.

29. Gorji, H.A., M. Etemadi, and F. Hoseini, Perceived organizational support and job involvement in the Iranian health care system: a case study of emergency room nurses in general hospitals. Journal of education and health promotion, 2014. 3 .

30. Higazee, M.Z.A., A. Rayan, and M. Khalil, Relationship between job stressors and organizational support among Jordanian nurses. American Journal of Nursing Research, 2016. 4(3): p. 51-55.

31. Gurdogan, E.P. and E.C. Uslusoy, The Relationship between Quality of Work Life and Happiness in Nurses: A Sample from Turkey. International Journal of Caring Sciences, 2019. 12(3): p. 1364. 